\title{
An Empirical Analysis of Child Care Demand in Switzerland
}

\author{
Silvia Banfi ${ }^{\mathrm{a}, *}$, Mehdi Farsi ${ }^{\mathrm{a}}$ and Massimo Filippini ${ }^{\mathrm{a}, \mathrm{b}}$ \\ ${ }^{a}$ ETH Zurich, Department of Management, Technology and Economics \\ Zürichbergstrasse 18, CH - 8032 Zurich, Switzerland \\ ${ }^{\mathrm{b}}$ University of Lugano, Department of Economics \\ Via G. Buffi 6, CH - 6904 Lugano, Switzerland
}

\section{Abstract}

This paper analyzes the demand of Swiss families for child care facilities. A choice experiment is used to study the effects of the facilities' characteristics as well as socio-economic factors on the selected child care mode. The experimental data are analyzed using a discrete choice model with multinomial logit specification. The results suggest that the demand for extra-familial day care could be considerably higher than that observed from the actual choices constrained by insufficient provision of affordable day care. The price, access, and the quality of service as well as parents' income and education have important impacts on the choice of the mode of care.

JEL classification code: C25, D12, J13

Keywords: Child care; Choice experiment; Discrete choice

\section{Acknowledgements}

A part of this study is based on the results of a joint research project (Stern et al., 2006) with INFRAS and Tassinari Beratung. The authors gratefully acknowledge the financial support of the Swiss National Science Foundation. They also wish to thank Rolf Iten, Susanne Stern, Sergio Tassinari and Ria Schrottman for their invaluable support throughout the project and Daniela Pióro for her excellent assistance. The authors are responsible for all remaining errors and omissions.

* Corresponding author 


\section{Introduction}

Although child care services are gaining some importance in Switzerland, the provision of extra-familial day care has not been fully developed (OECD, 1994). Day care facilities, organized as child-care centers or in family homes, are usually run privately. Mostly subsidized by the local governments, these services are very limited especially in the countryside and small towns. The pre-school care centers and the allocation offices for family day care homes have long waiting lists, particularly for subsidized providers and for children below two years of age. ${ }^{1}$ The non subsidized day care facilities are hardly affordable for most families. The high prices are often considered as a result of the strict regulatory framework and the attempt to guarantee a high quality of care (Stutzer and Dürsteler, 2005)². According to statistics about $9 \%$ of children younger than 6 years have regular visits to a child care centre while $6 \%$ are taken care of in family day care homes. However, given the limited availability and the uncertainty of obtaining a placement for their children, many parents who would potentially demand child care services might be excluded from the market.

The lack of services for supporting parents in their children's day care can have various negative social and economic consequences, for instance on the fertility rate (Schröder 2005), on women's labour supply (Stebler 1999), and on the integration possibilities of disadvantaged children. ${ }^{3}$ In order to improve the provision of child care centers and family day care homes, the Swiss government initiated an incentive programme for start-up financing of such services. This program is aimed at providing the greatest possible number of families with the

\footnotetext{
${ }^{1}$ Report of the Swiss Parliament, 10 March 2006 (Botschaft zum Bundesbeschluss über Finanzhilfen für familienergänzende Kinderbetreuung, 10. März 2006)

${ }^{2}$ For instance, the prescribed number of children per care-giver and the maximum size of the groups are significantly lower than in the contiguous countries.

${ }^{3}$ Stebler (1999) provides empirical evidence that the provision of child care facilities has a crucial impact on the working behavior of mothers in Switzerland. OECD (2004) reports that in Switzerland a relatively high share of working women work less than 30 hours a week (44.9\% as opposed to the overall OECD average of $18.8 \%$ ). Lanfranchi (2002) shows that schooling results of children of immigrants are highly related to their attendance of pre-school facilities.
} 
access to day care, support and instruction of their children by qualified care givers. Besides the positive effect on the cognitive and social development of children, such a program may have a positive impact on mothers' participation in the labour market and attenuate the problems related to aging of the population by increasing fertility rates.

From a policy standpoint a statistical estimation of potential child care choices can be very useful given the aim of the State to improve the provision of affordable child care facilities in Switzerland:

1. First, an effective promotion of child care facilities requires information about the parents' potential demand for different types of child care services. Especially as in certain cases, the alternative modes of day care could be considered to avoid the relatively costly child care centers.

2. Secondly, in order to achieve an optimal provision of day care system, it is essential to assess the sensitivity of the demand in response to variations in the service attributes such as price, distance and quality characteristics.

3. Finally, it is believed that the existing heterogeneity in the provision and types of (subsidized) child care across different areas ${ }^{4}$ creates an equity problem regarding both access and variety of choices. An equitable provision would require an estimation of potential demand based on demographic and socio-economic characteristics pertaining to various locations.

In principle, the data on child care choices can be based on revealed or stated preferences. The former method, used by virtually all previous studies, focuses on the households' actual deci-

\footnotetext{
${ }^{4}$ This heterogeneity is documented in Stern at al. (2006); Parlamentarische Initiative Anstossfinanzierung (2002); and different evaluations of the Swiss Labour Force Survey, Swiss Federal Statistical Office.
} 
sions. The stated preference method on the other hand, draws upon individuals' choices in hypothetical situations defined by the researcher. ${ }^{5}$

Given the actual state of day care provision in Switzerland, the observed utilization of child care services does not provide a realistic picture of potential demand. In fact, most often parents do not have several alternatives to choose from. In many cases only a single type of care is available to them. Therefore, the adopted mode of child care is not representative of the families' real preferences with sufficient provision. In fact, in this situation, the revealed approach could lead to biased predictions, as actual choice behavior reflects a combination of consumer preferences and often prevailing constraints, induced by current market conditions. Moreover, it is often difficult to identify the available choice set from which the actual care has been chosen. Therefore, the revealed preferences based on actual usage are not much helpful in eliciting consumers’ preferences, especially for assessing the potential responses to future provisions and extensions. In the stated preference approach, these problems are solved through preset choice conditions. However, this solution entails hypothetical choice sets, which might bring about a loss of precision, due to the potential risk of inconsistent decisions. Following the stated preference approach, this paper simulates families' decisions with hypothetical choice situations (so called vignettes or choice experiments) in which several modes of child care are offered and the respondents are asked to choose the alternative that suits them best. The data have been collected for a sample of about 600 families with at least one child of pre-school age. Each family has been provided with six different choice situations. A discrete choice econometric model has been applied to the recorded decisions in order to estimate the effect of various household characteristics and care attributes. In particular, the effects of price and quality of care as well as the impacts of other child care possibilities avail-

\footnotetext{
${ }^{5}$ For an overview of the general advantages and drawbacks of the two methods see for example Verhoef and Franses (2002) or Louviere et al. (2000).
} 
able to the family and the parents' current work status have been analyzed. This latter variable is considered to be exogenous to the demand on (hypothetical) child care facilities. ${ }^{6}$

The results point to a considerable variation in demand depending on several demographic characteristics. They also indicate that price and distance from home are the two most important factors that determine the families' choices. The data confirm that the potential demand at the present subsidized prices (for low and medium income families) is considerably higher than the actual provision of child care services. Especially, the demand for family day care homes is comparable to that of day care centers, which suggests that this option could be considered as an effective substitute.

The paper continues with a description of the methods and the model specification in Section

2. The experiment design, the survey procedures and the data description are presented in

Section 3. Section 4 provides the estimation results. The paper ends with a summary of the results, an interpretation of the main results and some comments on their policy relevance.

\section{Model}

There is a great quantity of papers applying the choice experiment approach for the estimation of demand for public (and private) goods. ${ }^{7}$ For a review of the history and an overview of the fields of application of choice experiment we refer to Champ et al. (2003). This approach has been frequently applied for the estimation of demand for public services, for example the demand of consumers for different health care plans or public health programs and services (Jan et al 2000; Gyldmark and Morrison, 2001; Harris, 2002), for the analysis of university choices (Oosterbeek et al., 1992; Soutar and Turner, 2002) or the evaluation of services offered by

\footnotetext{
${ }^{6}$ We consider the current employment situation of the parents as an explanatory variable for the hypothetical (future) choice of child care mode.

${ }^{7}$ Actually, the choice experiment approach, called also conjoint analysis, has its conceptual foundation in Lancaster's theory of consumer demand. This technique was used at first by marketing researchers, who recognized the importance of commodity attributes when designing new products (Champ et al. 2003).
} 
state-owned cultural sites (Mazzanti, 2003). To our knowledge such an experimental approach has never been applied in the analysis of child care demand.

Concerning the child care demand, there is a great body of international economic literature analyzing the demand for day care facilities, focusing mainly on the impact of service attributes especially prices, on demand (Hofferth and Wissoker, 1992; Chaplin et al., 1996; Van Horn et al. 2001). In particular a stream of this literature that focuses on the sensitivity of women's labor participation to changes in the price of day care services bears a considerable policy interest (Cleveland et al., 1996; Pungello and Kurtz-Costes, 1999; Powell, 2002; Del Boca et al., 2004). However, exploring the impact of child care provision on labor supply is beyond the scope of this paper. Here, the focus is on the evaluation of child-care demand and identifying its main determining factors through households’ preferences.

A large part of the analyses on child care demand is based on data from national surveys. The studies use cross sectional (Chaplin et al., 1996; Connelly and Kimmel, 2003) as well as longitudinal data (Leibowitz et al., 1992; Anderson and Levine, 2000). These surveys collect data on the actual child care choices of parents. In Switzerland, there are no national data available on this topic which could be used for forecasting demand. ${ }^{8}$ Further, since actual child care choices are often restricted by insufficient provision and access problems, they could be a poor indicator of the families’ preferences.

The general empirical results reported in the child care studies highlight the importance of several factors such as cost of care (Anderson and Levine, 2000; Chaplin et al., 1996), family income and child care tax credits (Hofferth and Wissoker 1992, Michalopoulos et al. 1992), children’s age (Leibowitz et al. 1992), mother’s working hours (Connelly and Kimmel, 2003) as well as other socio-economic characteristics on child care choice. Due to the great variation

\footnotetext{
${ }^{8}$ The only data available are those of the Swiss Labour Force Survey. This survey collects amongst others data on the child care choices of employed parents. Information on the prices of child care services and their availability are not collected.
} 
of the data used in these studies, comparison between the results of the studies is not always feasible.

From the econometric point of view, most of the papers employ a discrete choice analysis such as multinomial logit (Kreyenfeld and Hank 2000, Michalopoulos and Robins 2002, Del Boca et al. 2004) or probit (Anderson and Levine, 2000; Chevalier and Viitanen, 2002; Connelly and Kimmel, 2003; Del Boca et al., 2004). Further, a combination of discrete and continuous models has been used when the objective was to estimate the demand quantities (for example, the demand for hours of child care), for a specific child care mode (Powell, 1997). With reference to the random utility theory ${ }^{9}$, this paper models the choice of child care services for families with children younger than 5 years (before kindergarten). The underlying assumption is that families evaluate the characteristics of different child care services and then choose the service, which maximizes their utility. It is assumed that households consider the tradeoffs between benefits gained from day care services based on care attributes and the incurred costs including service prices and other opportunity costs depending on the household characteristics. According to the random utility theory, the utility of a service or good is considered to depend on observable (deterministic) components, including the attributes of the services and individual characteristics, plus a stochastic element that captures the influence of unobserved factors (cf. Louviere et al. 2000).

We represent the utility function of a child care mode $j$ for family $i$ as:

$$
U_{i j}=X_{i j} \beta_{j}+Z_{i} \gamma_{j}+\varepsilon_{i j}
$$

where $X_{i j}$ is the vector of attributes of alternative $j$ for household $i$; $Z_{i}$ is the vector of household characteristics; $\beta_{j}$ and $\gamma_{j}$ are the parameter vectors to be estimated; and $\varepsilon_{i j}$ is an independ-

\footnotetext{
${ }^{9}$ For a description of the random utility theory see Louviere et al. (2000) or Ben-Akiva and Lerman (1985).
} 
ently and identically distributed stochastic error term that represents the unobserved heterogeneity across households and alternatives. The adopted model in this paper is based on a multinomial logit model in which the error term $\varepsilon_{i j}$ is assumed to follow a type I extreme value (Gumbel) distribution. ${ }^{10}$ In this model, the probability of choosing alternative $j$ can be written as:

$$
\operatorname{Pr}\left(Y_{i}=j\right)=\frac{e^{X_{i j} \beta_{j}+Z_{i} \gamma_{j}}}{\sum_{j=0}^{J} e^{X_{i j} \beta_{j}+Z_{i} \gamma_{j}}} \text { for } j=0,1,2, \ldots, J
$$

where $J+1$ is the number of alternatives and $Y_{i}=0,1, \ldots, J$ is the individual $i$ 's response. As the model in equation (2) is indeterminate, it requires a normalization assumption, which can be obtained by setting $\beta_{0}$ and $\gamma_{0}$ equal to zero. Thus, equation (2) can be written as:

$$
\operatorname{Pr}\left(Y_{i}=j\right)=\frac{e^{X_{i j} \beta_{j}+Z_{i} \gamma_{j}}}{1+\sum_{j=1}^{J} e^{X_{i j} \beta_{j}+Z_{i} \gamma_{j}}} \text { for } j=0,1,2, \ldots, J, \beta_{0}=\gamma_{0}=0
$$

where alternative $j=0$ is considered as the comparison outcome.

It is worth noting that in this study the households are offered repeated choice situations and a more accurate presentation of the model should consider an index for the choice situation (card). Moreover, the number of alternatives is set equal to four. The model in equation (3) can thus be written as:

$$
P_{i c j} \equiv \operatorname{Pr}\left(Y_{i c}=j\right)=\frac{e^{X_{i c j} \beta_{j}+Z_{i} \gamma_{j}}}{1+\sum_{j=1}^{3} e^{X_{i c j} \beta_{j}+Z_{i} \gamma_{j}}} \text { for } j=0,1,2,3, \beta_{0}=\gamma_{0}=0
$$

where $c$ is the choice-situation (card) number. Notice that the choice attributes vary across different cards, but the parameters are alternative-specific.

\footnotetext{
${ }^{10}$ For more details about the multinomial logit model see Greene (2003), chapter 21.
} 
The marginal effects of the continuous explanatory variables are calculated as the partial derivative of the probability of outcome $j$, that is: $P_{j}$, with respect to the explanatory variable $x$, which is an element of the explanatory vector $[X, Z]$. The marginal effect and elasticity of a continuous variable $x$ can thus be obtained respectively from:

$$
\begin{gathered}
\frac{\Delta P_{j}}{\Delta x} \cong \frac{\partial P_{j}}{\partial x}=P_{j}\left[\beta_{j}^{x}-\sum_{k=1}^{3} P_{k} \beta_{k}^{x}\right] \text { for } j=0,1,2,3, \beta_{0}^{X}=0 \\
\varepsilon_{x}=\frac{\partial P_{j}}{\partial x} \frac{x}{P_{j}}
\end{gathered}
$$

where $\beta_{k}^{x}$ represents the coefficient related to outcome $k$, of explanatory variable $x$, that is the corresponding element of the parameter vector $[\beta, \gamma]$. Similarly, the marginal effects for dummy variable $x$ can be obtained from the following equation:

$$
\frac{\Delta P_{j}}{\Delta x}=P_{j}(x=1)-P_{j}(x=0)
$$

The model's explanatory variables include several child care attributes such as price, distance from home and quality of the service. In line with previous empirical studies the household's socio-economic characteristics such as parents' education, income and work status are also included. Since any additional variable requires three more parameters in the model, we tried to limit the number of parameters to a reasonable number. The final model specification was selected using a series of Wald tests to identify and exclude the variables that have no statistically significant effect in any outcomes. Therefore, some of the variables in the data, which would have otherwise required several dummy variables, have been reduced to a single dummy. ${ }^{11}$ A list of the variables and their definition are provided in Section 4.

\footnotetext{
${ }^{11}$ For instance, the mother's education is available in 13 categories, but after controlling for other variables only mothers with university degrees showed significant difference from others. Child's age and gender categories had no significant effect on choice probabilities. Thus, only one dummy variable with relatively important effect has been included. Similarly, the scheduling flexibility, which has been defined in 5 categories, was shown to be significant only when one-month-ahead scheduling is required. Finally, the measures related to opening hours of child-care centers did not appear to be significant.
} 
It is reasonable to assume, as in any grouped data, that the errors can be correlated across the observations that belong to the same household. Here, the correlation within household observations is considered by robust standard errors with the cluster option in Stata program. ${ }^{12}$ In this method the errors are only required to be independent across groups and can be correlated within groups. Consequently, the variations within groups contribute little to the estimation precision. The standard errors are therefore more realistic than those obtained with the independence assumption, which may be under-estimated.

\section{Experiment design and data description}

The data used in this paper are collected using a choice experiment approach. This approach initially proposed by Louviere and Hensher (1983), consists of asking a number of respondents to choose one among several alternatives characterized by various attributes. Within the range of non-market valuation techniques, choice experiment is most appropriate for capturing the implicit values of a good or service as a whole or its given attributes (Birol et al., 2005).

Of course, the choice experiment approach has also some limitations. ${ }^{13}$ One disadvantage is linked to the cognitive skills which are required from respondents when choosing the utility maximizing alternative from a complex choice situation. This complexity can lead to decisions which do not reflect a utility maximization process but rely on short-cuts. This is the case for example when respondents decide by considering just one attribute instead of the entire set of attributes. In order to reduce the cognitive difficulties, the hypothetical choice situation should be defined by a limited number of attributes. As a consequence, the characteristics used in our choice experiment have been chosen with particular accuracy and were

\footnotetext{
${ }^{12}$ See Moulton (1990) for more details about heteroscedasticity in grouped data, and Rogers (1993) for the clustering approach.

${ }^{13}$ For a more detailed overview see for example Bateman et al. (2002).
} 
collected with a separate survey which allowed identifying the most important characteristics for the choice of child care services. Some evidence for the importance of the child care characteristics selected for the choice experiment was also given by the literature reviews.

The study design, in particular the choice of the attributes as well as their levels, can have an impact on the choice experiment's results, which is another disadvantage of the method. In this regard it has to be considered that this is the case with all stated preference techniques. Another problem mentioned in the literature ${ }^{14}$ is linked with the assumption that the sum of the attributes' values sum up to the value of the whole good, although not all attributes can be considered in the choice experiment ${ }^{15}$. Although it is important to consider these limitations when choosing an evaluation technique, we believe that in our case the advantages of the use of a choice experiment method prevail over the drawbacks. Overall, we judge this method as interesting and appropriate for estimating the demand for hypothetical ${ }^{16}$ child care facilities. In this paper the experiment simulates a choice situation in which the respondent is asked to choose one care mode among several options. Each option is characterized by a series of attributes. The range of parameters and attributes are chosen within a realistic range comparable to the actual state in Switzerland.

The extra-familial day care for children can be classified in three main categories:

1. Child care center: Day care provided by professional staff with several children in a facility, other than private residence, which is specifically equipped for this purpose.

2. Family day care home: Day care provided by a parent who has one or more children of their own. The children are looked after in the caregiver's private residence.

3. Baby-sitter: Care provided by a private individual at home.

\footnotetext{
${ }^{14}$ Bateman at al. (2002), Hanley et al. (2001)

${ }^{15}$ In this case, the value is captured in the constant term.

${ }^{16}$ The child care facilities are hypothetical in terms of not available for a large share of parents.
} 
In the experiment the alternatives are organized in four modes including the above alternatives plus a fourth option labeled as private care, that represents parental care as well as all other options arranged within the circle of relatives and friends. In contrast to the other types of care, the private care is unpaid. In each choice situation the respondent has access to one option from each the three alternatives. This is more or less similar to the actual situations, in which the availability of multiple options of a single mode happens very rarely.

The external child care modes were characterized by the following attributes:

1. Price for half a day care: In order to simulate the customary pricing policy in Switzerland the prices are selected from an interval proportional to the household's income. Thus, the hypothetical prices consider automatically income difference between the rural and urban areas. The price of the child care center has been set between 0.3 and $0.6 \%$ of the family's income per half-day of care. The price of the family day care home was set slightly lower that is, between 0.2 and $0.5 \%$ of the family’s income for half a day. The average price level corresponds approximately to the price set currently by the child care facilities. Finally, the price for the nanny option was selected in a range similar to the actual market rates namely, between 60 and 100 Swiss francs $(\mathrm{CHF})^{17}$ per half a day.

2. Distance from home: The distance was set between 5 and 25 minutes without specifying the transport mode. ${ }^{18}$

3. Opening hours: For each alternative five different levels of opening hours were defined. Child care centers are usually open from Monday through Friday. For the family day care home and the baby-sitter, some choice cards considered availability of care on Saturday and Sunday. The opening hours varied between 9 and 14 hours a day.

\footnotetext{
${ }^{17} 1 \mathrm{CHF} \approx 0.6 €$

${ }^{18}$ The families were asked to assume that they took their usually preferred transport mode. We wanted to avoid the possibility of refusal of an alternative only because of the suggested transport mode. The distance for the nanny alternative is naturally set to zero.
} 
4. Number of children per staff member: This characteristic represents a quality aspect of the care. The number of children per care-giver varied between 3 and 7 children for the child care center and between 3 and 6 for the family day care home.

5. Flexibility: This attribute represents the scheduling flexibility. In the most restrictive form, the child care service is available only on certain days with the possibility of rescheduling on a monthly basis. In the most flexible form there is the possibility to use the service at short notice and without restriction on the number of hours.

Table 1 shows an example of a choice situation that has been presented to the families. Each family has been presented six different choice cards. Respondents were asked to imagine that the three offered alternatives to private care are available in their residence area and that can be obtained without the usually required registration in the waiting lists.

A full fractional design of all levels of the attributes would require a very high number of cards. Therefore, the different levels of the characteristics were combined using an orthogonal factorial design (Louviere et al. 2000, Champ et al. 2003). Using this approach redundant combinations of the levels of the characteristics are omitted. Thus it was possible to cover the whole space of attribute combinations with a limited number of alternatives. This allows maximizing the information obtained by the choice experiment, without presenting all combination possibilities to the respondents. 
Table 1: Example of a choice card

\begin{tabular}{|c|c|c|c|c|}
\hline \multirow{2}{*}{$\begin{array}{l}\text { SITUATION } 1 \\
\text { CHARACTERISTICS }\end{array}$} & \multicolumn{4}{|c|}{ Child care alternatives } \\
\hline & $\begin{array}{l}\text { ALTERNATIVE } 1 \\
\text { Child care center }\end{array}$ & $\begin{array}{l}\text { ALTERNATIVE } 2 \\
\text { Family day care }\end{array}$ & $\begin{array}{c}\text { ALTERNATIVE } 3 \\
\text { Nanny }\end{array}$ & $\begin{array}{c}\text { ALTERNATIVE } 4 \\
\text { Private care }\end{array}$ \\
\hline Price for half a day & CHF 40 per child & CHF 30 per child & CHF 60 & \\
\hline Distance from home & 10 minutes & 15 minutes & - & \\
\hline Opening hours & $\begin{array}{l}\text { Monday-Friday } \\
7 \text { a.m.- } 6 \text { p.m. }\end{array}$ & $\begin{array}{l}\text { Monday-Friday } \\
8 \text { a.m. - } 4 \text { p.m. }\end{array}$ & $\begin{array}{l}\text { Monday-Saturday } \\
8 \text { a.m. }-4 \text { p.m. }\end{array}$ & $\begin{array}{l}\text { I solve the care of } \\
\text { the child in a private }\end{array}$ \\
\hline $\begin{array}{l}\text { Number of children per } \\
\text { staff-member }\end{array}$ & 5 & 4 & - & way. \\
\hline Flexibility of the service & $\begin{array}{l}\text { Fixed day, monthly } \\
\text { scheduling }\end{array}$ & $\begin{array}{l}\text { Monthly scheduling } \\
\text { without fixed days }\end{array}$ & Weekly scheduling & \\
\hline My choice is: & $\square$ & $\square$ & $\square$ & $\square$ \\
\hline & $\sqrt{3}$ & $\sqrt{3}$ & Л & \\
\hline $\begin{array}{l}\text { Days per week } \\
\text { (e.g. } 1 \text { day, } 2.5 \text { days...) }\end{array}$ & $\ldots \ldots \ldots \ldots \ldots \ldots$ & (n)................ & (n................ & \\
\hline
\end{tabular}

The respondents were initially a random sample from the population of families living in nine Swiss cantons that participated in the study, reflecting all three linguistic regions of Switzerland. ${ }^{19}$ The municipalities in the selected cantons currently offer a number of child care facilities. Thus, we could assume that some of the parents have already used this service. In order to attain a balanced sample across rural and urban areas (according on the distribution of the sample frame population), special attention was put on the regional distribution of the households in the sample. Within the cantons, the parents of children aged below four years were chosen randomly from a database of the market research company commissioned with the survey. The families were first contacted by phone and asked about their family composition and the age of the children. The families with at least one child of four years old or younger were asked further questions on their actual child care choices as well as some socioeconomic characteristics, including income. In a second stage, the families were mailed six choice cards with the alternatives day care modes and the related instructions. In a third stage,

\footnotetext{
${ }^{19}$ The participating cantons are: Bern, Luzern, Zug, Baselstadt, Aargau, Ticino, Vaud, Wallis and Jura. Switzerland has 26 cantons.
} 
they were contacted by phone and asked to reveal their choices. The average length of the interview was about 24 minutes. The survey was carried out between October 2003 and July 2004.

From the 694 households that participated at the first stage of the survey $88 \%$ have completed the choice cards and participated at the second part of the survey. The final sample including the valid observations used for this study consists of 2972 records from 597 families. Thus it is possible that the final sample is not representative of the initial population. However, a primary analysis of several household characteristics such as income, household size and parents' age and work status suggests that the composition of the households included in the final sample is not significantly different from that of the initial sample in regards to these variables. Considering this and in view of the relatively high participation rate, we contend that the sample can be considered as a fairly representative sample for the participating cantons. The families include households living in both rural and urban areas with about $61 \%$ in the latter group, and both German-speaking (58\% of households) and the French and Italianspeaking (42\%) parts of Switzerland.

A descriptive summary of the sample used in the econometric analysis is given in table 2 . 
Table 2: Descriptive statistics of socioeconomic characteristics $(\mathrm{N}=597)$

\begin{tabular}{|c|c|c|c|c|}
\hline & Mean & Std. Dev. & Minimum & Maximum \\
\hline Child is one-year old or younger & 0.268 & 0.443 & 0 & 1 \\
\hline One parent's 1st nationality is not Swiss & 0.206 & 0.405 & 0 & 1 \\
\hline Rural household & 0.390 & 0.488 & 0 & 1 \\
\hline French/Italian speaking region & 0.414 & 0.493 & 0 & 1 \\
\hline Additional child(ren) younger than 5 & 0.382 & 0.486 & 0 & 1 \\
\hline Additional child(ren) of age 5-12 & 0.405 & 0.491 & 0 & 1 \\
\hline Additional child(ren) of age 13-18 & 0.049 & 0.215 & 0 & 1 \\
\hline Mother's age & 33.662 & 4.188 & 22 & 49 \\
\hline Mother has a university degree ${ }^{a}$ & 0.152 & 0.360 & 0 & 1 \\
\hline Mother works $50 \%$ or more & 0.256 & 0.437 & 0 & 1 \\
\hline Household monthly income in CHF $1000^{\mathrm{b}}$ & 6.015 & 2.178 & 1 & 12 \\
\hline The respondent is the father ${ }^{c}$ & 0.095 & 0.294 & 0 & 1 \\
\hline Father's job is not a normal daily job ${ }^{\mathrm{d}}$ & 0.186 & 0.389 & 0 & 1 \\
\hline Main child-care provided by parents & 0.591 & 0.492 & 0 & 1 \\
\hline Main child-care by relatives/friends & 0.258 & 0.438 & 0 & 1 \\
\hline Number of choice situations (cards) & 4.978 & 0.960 & 2 & 6 \\
\hline
\end{tabular}

${ }^{\mathrm{a}}$ University degree means an education level of University or professional college.

${ }^{\mathrm{b}}$ Monthly income is available as a multiple of thousand Swiss Francs (e.g. 3 means between 3000 and 4000).

${ }^{\mathrm{c}}$ In these households the father is the main person in charge of child-care arrangements.

${ }^{\mathrm{d}}$ Also includes cases in which father does not have any employment.

In the initial part of the questionnaire respondents were asked about their actual day care choices. The respondents reported the two options they have used most often. ${ }^{20}$ Only $10.2 \%$ of the families use day care centers and $4.7 \%$ use the services of family day care homes as their primary option. As for the nanny option, only one household reported to have used this option as their main child care. The rest of the sample, namely 84.9 percent of the families report a private alternative as their main care option. Overall, considering the two reported main child-care options, the data show that 78.7 percent of the families do not actually use

\footnotetext{
${ }^{20}$ Among the families who reported non-zero values, the median number of hours of care used for the main child-care option is 15 hours per week and that of the secondary choice is about 5 hours per week.
} 
extra-familial day care; $14.6 \%$ reported to use a child care center; $6.2 \%$ family homes; and only $0.5 \%$ (3 families) use baby-sitters. ${ }^{21}$

The distribution of hypothetical choices shows that the child care center and family home alternatives have been chosen respectively in $28.0 \%$ and $22.9 \%$ of the cases. While the private option has been selected in $44.8 \%$ of the cases, only in $4.3 \%$ of the hypothetical observations the baby-sitter alternative has been chosen. 181 households (about 30\% of the respondents) have always chosen the private alternative. This suggests that these households have probably access to a private source of care and are not responsive to any changes in the attributes of other alternatives. On the other hand, about 69 percent of the households have chosen at least once, a child-care center or a family home option. Only a small fraction of families (about 7\%) have always chosen the same non-private option, suggesting that there is no strong preference for any one of these choices.

Given that in the experiment design the values of the choice attributes are simulated based on the real world, the data suggest that the positive response to the child-care center and family home options could be increased to levels as much as twice or three times the actual utilization rates. However, given that many families use the external care as their complementary day care option, the primary and secondary actual choices may understate the actual usage of the extra-familial care.

A descriptive summary of the explanatory variables used in the econometric analysis is given in table 3.

\footnotetext{
${ }^{21}$ The number of observations of parents using formal care modes is too low for carrying out estimations using the actual choices. In addition, there is no information on alternative care modes (presence of such alternatives, characteristics).
} 
Table 3: Descriptive statistics of the characteristics of the chosen alternatives $(N=2972)$

\begin{tabular}{l|cccc} 
& Mean & Std. Dev. & Minimum & Maximum \\
\hline Day Care Center price (CHF/half-day) & 29.103 & 11.362 & 6 & 60 \\
Family Home price (CHF/half-day) & 23.093 & 10.307 & 3 & 50 \\
Baby Sitter price (CHF/half-day) & 75.760 & 13.877 & 60 & 100 \\
Number of children per person (DCC) & 5.041 & 1.399 & 3 & 7 \\
Number of children per person (FH) & 4.489 & 1.124 & 3 & 6 \\
Distance from DCC (multiples of 5 minutes) & 3.002 & 1.418 & 1 & 5 \\
Distance from FH (multiples of 5 minutes) & 3.029 & 1.397 & 1 & 5 \\
FH is open at least 1 week-end day & 0.401 & 0.490 & 0 & 1 \\
DCC requires 1-month-ahead scheduling & 0.397 & 0.489 & 0 & 1 \\
FH requires 1-month-ahead scheduling & 0.392 & 0.488 & 0 & 1 \\
\hline
\end{tabular}

\section{Estimation results}

The regression results are given in table 4. The model is based on four alternatives. Before discussing the results, we turn to two modeling issues that we considered. First, the multinomial logit model assumes that the ratio of odds between a pair of alternatives does not depend on the third alternative. This assumption referred to as independence of irrelevant alternatives (IIA) can be violated particularly when the decision is made in a nested manner. One might argue that families first decide whether they would like to keep their child at home (babysitter option) and then depending on this first-stage decision they examine the external options (child care center and family day care home). In this case, the IIA assumption is not satisfied because the exclusion of one external care is likely to result an increase in the other external care but no considerable change in the home option. We used a series of Hausman tests to test the IIA hypothesis with respect to each one of the alternatives. The results are in favor of the independence assumption with relatively high p-values. 
Our second concern was the fact that the response to the baby-sitter outcome is quite low (about 4.3\%), which might decrease the model’s statistical efficiency through small sample errors. We therefore decided to consider an alternative analysis in which we ignore the babysitter option and exclude the households that have chosen this option from the sample. The results in terms of marginal effects on the external alternatives are very similar to those re-

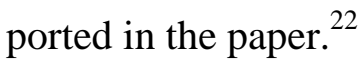

The coefficients listed in table 4 show the effects of the explanatory variables on the probability of choosing child care center, family day care home and the baby-sitter option compared to the base category (private option). Many of the coefficients are statistically significant and the model shows a reasonable explanatory power as indicated by a $54.8 \%$ rate of correct prediction of the choices in the sample. Most of the coefficients have the expected sign and the main choice attributes such as price and distance are highly significant in both choices.

Table 5 provides the marginal effects along with the elasticity estimates for the continuous variables at the sample mean. ${ }^{23}$ Only the significant effects at 5\% significance level are included in the table.

The results indicate that many of the household characteristics have a significant effect on choice probabilities. For instance immigrant families are on average about 10 percentage points more likely to choose child care center. Compared to German-speaking households, families residing in French/Italian-speaking regions are about 5\% more likely to use nonprivate external child-care.

The above results are more or less consistent with the actual choice of these families. Among the 597 households in our sample, about 10\% are actually using a child care center, and about 5\% a family day care house as their main child-care option. These numbers increase to about

\footnotetext{
${ }^{22}$ The results of the alternative regressions are available upon request from the authors.

${ }^{23}$ The marginal effects and elasticities were also estimated for each observation and then averaged over the sample. The results (available upon request) are not much different from the estimated values at the sample mean.
} 
15 and 10 percent (respectively for child care center and family day care home) among the 123 immigrant families (with at least one foreign parent) in the sample. As for the actual choice among the 233 'Latin' families in the sample, the distribution changes to about $15 \%$ for the child care center and $8 \%$ for the family day care home alternative.

Table 4 shows that there is no statistically significant difference between the choices of the residents of rural and urban areas. However, among the 233 rural households in the sample, only about $9 \%$ reported to actually use an external child-care (child care center or family day care home) as their main option. This can be explained by the fact that access to child-care services is relatively limited in rural areas.

The presence of a sibling has a significant effect in choice probabilities. The estimation results suggest that the households with additional children older than 5 are less likely to use a non-private care option. However, the effect depends on the age category of the sibling(s): Households with teenage children are on average $14 \%$ less likely to choose a family day care home whereas the presence of children between 5 and 12 decreases the child care center incidence by 0.09 on average. Families with more than one preschool-age children are 2 percent more likely to hire a baby-sitter.

Older mothers are significantly more likely to choose an external day care especially a childcare center. Mothers with university degrees are on average 9\% more likely to use child care centers. The results also suggest that the demand for non-private child care increases with family income. However, the effect for the family home option is not statistically significant. As for child care centers and baby-sitters the demand elasticity of income is respectively 0.56 and 0.92. As expected because of relatively high prices of baby-sitters the demand for this is relatively sensitive to income. 
Table 4: Regression results

\begin{tabular}{|c|c|c|c|c|c|c|}
\hline & \multicolumn{2}{|c|}{ Child care center } & \multicolumn{2}{|c|}{$\begin{array}{c}\text { Family day care } \\
\text { home }\end{array}$} & \multicolumn{2}{|c|}{ Baby sitter } \\
\hline & Coeff. & $\begin{array}{l}\text { Standard } \\
\text { error }\end{array}$ & Coeff. & $\begin{array}{l}\text { Standard } \\
\text { error }\end{array}$ & Coeff. & $\begin{array}{c}\text { Standard } \\
\text { error }\end{array}$ \\
\hline Child is one-year old or younger & -.046 & .191 & .303 & .194 & .167 & .324 \\
\hline One parent's nationality is not Swiss & $.564 * *$ & .216 & .285 & .233 & -.197 & .373 \\
\hline Household living in rural area & -.305 & .173 & -.024 & .178 & -.381 & .313 \\
\hline French/Italian speaking region & $.341 *$ & .175 & $.399 *$ & .180 & -.297 & .317 \\
\hline Additional child(ren) younger than 5 & .073 & .184 & .199 & .188 & $.585 *$ & .299 \\
\hline Additional child(ren) of age 5-12 & $-.554 * *$ & .204 & -.198 & .202 & -.057 & .328 \\
\hline Additional child(ren) of age 13-18 & -.573 & .375 & $-1.385^{* *}$ & .521 & -.247 & .567 \\
\hline Mother's age & $.071 * *$ & .023 & $.049 *$ & .023 & .070 & .042 \\
\hline Mother has a university degree & $.520 *$ & .259 & .295 & .257 & -.132 & .370 \\
\hline Mother works $50 \%$ or more & .092 & .222 & -.145 & .223 & .154 & .342 \\
\hline Monthly income in $1000 \mathrm{CHF}$ & $.163^{* *}$ & .060 & .083 & .060 & $.222 *$ & .094 \\
\hline Respondent is the father & $-.729 *$ & .310 & $-.757 *$ & .321 & .143 & .450 \\
\hline Father has not a normal daily job & -.228 & .219 & .011 & .234 & -.404 & .386 \\
\hline Main child-care by parents & $-1.36 * *$ & .255 & $-1.48 * *$ & .295 & $-1.53^{* *}$ & .425 \\
\hline Main child-care by relatives/friends & $-1.37 * *$ & .268 & $-1.12 * *$ & .300 & $-1.33^{* *}$ & .463 \\
\hline Price (CC) & $-.052 * *$ & .007 & $.016 *$ & .008 & -.003 & .013 \\
\hline Price (FH) & .013 & .007 & $-.049 * *$ & .007 & .001 & .012 \\
\hline Price (BS) & .000 & .004 & .002 & .004 & $-.035^{* *}$ & .010 \\
\hline Number of children per person (CC) & $-.158 * *$ & .036 & -.007 & .034 & .034 & .060 \\
\hline Number of children per person (FH) & -.023 & .040 & $-.101 *$ & .046 & .072 & .093 \\
\hline Distance from CC (in 5 minutes) & $-.313^{* *}$ & .037 & $.072 *$ & .034 & -.023 & .077 \\
\hline Distance from FH (in 5 minutes) & $.092 * *$ & .035 & $-.364 * *$ & .038 & .026 & .071 \\
\hline FH is open at least 1 week-end-day & -.179 & .094 & $.253^{* *}$ & .099 & -.370 & .206 \\
\hline CC requires 1-month-ahead scheduling & -.154 & .096 & -.049 & .099 & -.046 & .195 \\
\hline FH requires 1-month-ahead scheduling & .136 & .097 & -.190 & .107 & -.007 & .189 \\
\hline Constant & .152 & .896 & -.041 & .902 & -2.541 & 1.931 \\
\hline
\end{tabular}

597 households, 2972 observations, Pseudo $\mathrm{R}^{2}=0.141$, logL= -3036.4, Correct prediction: 54.8\%

Alternatives: Child care center (CC); Family day care home (FH); Baby-sitter (BS); Private (comparison group)

* significant at .05; ** significant at .01 
Table 5: Marginal effects and elasticities (at the sample mean) of significant variables (at $\mathbf{p}<.05$ )

\begin{tabular}{|c|c|c|c|c|c|c|}
\hline & \multicolumn{2}{|c|}{ Child care center } & \multicolumn{2}{|c|}{ Family day care home } & \multicolumn{2}{|c|}{ Baby sitter } \\
\hline & $\begin{array}{c}\text { Marginal } \\
\text { effect }\end{array}$ & Elasticity & $\begin{array}{c}\text { Marginal } \\
\text { effect }\end{array}$ & Elasticity & $\begin{array}{c}\text { Marginal } \\
\text { effect }\end{array}$ & Elasticity \\
\hline One parent's nationality is not Swiss & 0.10 & & & & & \\
\hline French/Italian speaking region & 0.05 & & 0.05 & & & \\
\hline Additional child(ren) younger than 5 & & & & & 0.02 & \\
\hline Additional child(ren) of age 5-12 & -0.09 & & & & & \\
\hline Additional child(ren) of age 13-18 & & & -0.14 & & & \\
\hline Mother's age & 0.01 & 1.32 & 0.004 & 0.58 & & \\
\hline Mother has a university degree & 0.09 & & & & & \\
\hline Monthly income in $1000 \mathrm{CHF}$ & 0.02 & 0.56 & & & 0.01 & 0.92 \\
\hline Respondent is the father & -0.10 & & -0.08 & & & \\
\hline Main child-care by parents & -0.16 & & -0.15 & & -0.03 & \\
\hline Main child-care by relatives/friends & -0.18 & & -0.10 & & -0.02 & \\
\hline Price (CC) & -0.01 & -1.20 & 0.01 & 0.76 & & \\
\hline Price (FH) & & & -0.01 & -0.98 & & \\
\hline Price (BS) & & & & & -0.001 & -2.58 \\
\hline Number of children per person (CC) & -0.03 & -0.59 & & & & \\
\hline Number of children per person (FH) & & & -0.02 & -0.34 & & \\
\hline Distance from CC (in 5 minutes) & -0.06 & -0.74 & 0.03 & 0.42 & & \\
\hline Distance from FH (in 5 min.) & 0.04 & 0.44 & -0.07 & -0.94 & & \\
\hline FH is open at least 1 week-end-day & & & 0.06 & & & \\
\hline
\end{tabular}

Child care center (CC); family day care home (FH); baby-sitter (BS) 
The results also suggest that with a given education and income, the parents' working status does not have any significant direct effect on their choices. The working status represents the actual employment situation that can be considered as exogenous to the hypothetical choice of the child care mode. In $9.5 \%$ of the households in the sample the father has responded to the survey (see table 2). These cases generally correspond to the households in which the responsibility of child care is mainly with the father rather than the mother. The results suggest that these households are less likely to choose an external option (by about 10 and 8 percentage points respectively for child care center and family home options). Our data on the couples’ working status show that in these households, it is relatively likely that the father does not work and the mother has a full-time job. This suggests that the father-respondent dummy might capture some of the effects of the couple’s working status. However, our preliminary regressions indicate that if this dummy is replaced with the father's working status variables such as percentage of working hours or full-time job dummies, their effects are not significant. Therefore this dummy appears to capture some other household characteristics as well. In fact, the rather "unconventional” feature of these households, as the actual outcome of the households' bargaining process about the organization of child care, could be linked to some unobserved characteristics of those families which also affect the choice for extra-familiar care.

The last two household characteristics in the model measure the access to a private care. As expected, households that have access to parental care (the main actual child care provided by one or both parents) are about $15 \%$ less likely to choose a child care center or a family day care home. Similarly, the households with access to day care provided by relatives or friends are less likely to choose a non-private care. However, the effect is much higher with respect to the child care center, suggesting that families with access to a private child-care are relatively more willing to substitute a non-parental care for a family day care home rather than a care 
center. These families are also less likely to choose the baby-sitter option. It should be noted that given the rate of positive response to each outcome the effect of these two variables is quite substantial in all three outcomes.

Our additional regressions indicate if the nine choice attributes are excluded from the model, the pseudo R-square's value falls to .060, suggesting that the choice attributes explain a large fraction of the variation in choice probabilities. The most important attribute is price. As seen in table 4, in the case of external care types (CC and $\mathrm{FH}$ ) the coefficient of own price is more or less similar. In fact statistical tests show that these coefficients are not significantly different from each other. This also applies to the cross price effects, namely the effect of CC price on FH choice is the same as that of FH price on CC choice. This result suggests that regarding price changes, households have a similar response across these two options. The results (table 5) show that the own price elasticity of both external care types is about -1.0 to -1.2 . This suggests that a price increase of $10 \%$ will reduce the demand by about 10 to 12 percent. The cross price elasticities are significantly lower. According to the estimations, the demand for child care centers and family day care homes respectively increase by about $5 \%$ to $8 \%$ if the price of the alternative external care increases by $10 \%$.

The baby-sitter option's own price elasticity is estimated at about 2.6, suggesting a very high sensitivity of demand to prices. The results also indicate that there is no significant price effect between the baby-sitter option and the two external services. This is also valid for all other attributes. Namely, none of the changes in attributes of any of the external care alternatives has any significant effect on the demand of baby-sitter care. This can be partly due to the very small positive response to this option.

The ratio of children per care-person does not have a significant 'cross' effect, that is changing this factor in one alternative does not change the demand for the other alternative. Here again the own elasticities are slightly but not significantly different across alternatives. The 
results suggest that the probabilities decrease with less staff, the respective elasticities being 0.59 and 0.34 for the alternatives child care center and family day care home. The distance to the child care provider significantly affects the probabilities. The own distance elasticity is respectively -0.74 and -0.94 for child care center and family day care home choices and the cross distance elasticities are about 0.4 in both cases. The distance elasticities are not significantly different across the two alternatives.

If families day care homes function during the weekend, their demand will increase by about $6 \%$ on average, but it does not affect the child care center demand. The scheduling flexibility has no significant effect. However, if the family day care homes require one-month-ahead scheduling, their demand may slightly fall, while the demand for child care centers can rise by almost the same amount. This may suggest that families are willing to plan their child-care demand with a center but not with a family home.

\section{Summary and conclusions}

Although extra-familial child care services have gained importance in Switzerland, the provision of day care facilities has not been fully developed. Most families cannot afford or do not have access to private non subsidized day care facilities that are generally limited to large city centers.

In order to improve the provision of child care centers and family day care homes, the government has initiated an incentive program for start-up financing of child care services. An effective promotion of child care facilities by policy makers requires detailed information about the conditions under which parents are willing to use such services.

Due to the current limitations of the child care market in Switzerland, we have used a stated preferences approach in order to elicit the preferences of households regarding the type of provided care. By applying a choice experiment it was possible to identify the importance of 
the characteristics of child care facilities. The choice experiment considered four modes of day care: the child care center, the day care family home, the baby-sitter and the private solution. The characteristics considered in the choice experiment were the price, the distance from home, the number of children per staff member, the opening hours and the flexibility to adapt the time of care to different needs.

The sample consists of 597 families living in Switzerland covering households living in all parts of Switzerland. The comparison of the actual choices and the hypothetical choices shows a considerable increase in demand for child care centers and family day care homes. This can be partly explained by the current lack of supply. The results suggest that the existing subsidy programs cannot fill the observed gap between the actual market conditions and the potential demand of affordable services. Therefore, to the extent that the families' preferences can be used as a guide, the governments could put greater efforts in promoting external child care services. Actually, the promotion of this kind of public services can have positive social and economic impacts (on the fertility rate, labour supply of women, and on the integration possibilities of disadvantaged children).

The results of a multinomial logit regression model indicate that many of the household characteristics have a significant effect on the choice probabilities. In particular, mother's age and education have positive effects on the incidence of external care options especially child-care centers. This result suggests that mothers with higher education and experience, who have relatively good working possibilities, are more likely to benefit from external child care services. Immigrant families are relatively more likely to choose child-care centers. This group could therefore be an appropriate target group for policies that aim at social integration.

The estimation results also suggest that the factors related to the parents' current work status, do not have a significant effect on families' hypothetical choice of child care. Suggesting that both working and non-working mothers are equally interested in child care services, this re- 
sult could be interpreted as an indication that parents might change their work status if their child care possibilities change. This may be true in particular for all the mothers who in the current situation have to renounce to an employment because of the lack of affordable child care services.

Another interesting result is that except for the baby-sitter option, the household's income has a relatively small effect in their choice of child-care. This can be explained by the fact that the experiment was based on prices set more or less proportional to the family's income, as it is the case for the Switzerland's dominantly subsidized child care services. The results also point to a considerable potential demand for child-care services among those households that use private solutions such as parents or relatives' aid. Also the family's cultural background appears to play a role in their choice: Families living in the French or Italian-speaking parts of Switzerland are more likely to choose external day care, whereas those living in Germanspeaking regions tend to prefer the private solution.

In addition to the socio-demographic variables, the choice attributes explain a large fraction of the variation in choice probabilities. The most important attribute is price with an elasticity of about -1 for child care center and family day care home and -2.6 for the baby-sitter option. The distance to the day care provider and the ratio of children per care-person have also a significant and negative effect on the demand. The cross elasticities between the two external care alternatives indicate that families to some extent, substitute the child-care center and family-home options.

In general, the results suggest an important potential demand for non-parental day care facilities in Switzerland. The demand for these institutions depends mainly on their characteristics with the affordability (price) and access (distance) being the most important factors. That is, the demand is sensitive to explicit costs (through prices) but also to travel costs (including time costs). 
While the demand for external day care varies across different groups of population, we can observe that overall, there are no strong preferences for one specific child care mode. As a consequence, an effective promotion policy should promote diversified and flexible child care alternatives. In fact the optimal form of day care with maximum accessibility and minimum costs could vary across different communities. For instance, family day care homes can be considered as a more economical alternative to child care centers, in particular in rural regions where the number of children is not sufficient to justify the creation of a center. Given the relatively high price elasticity, price subsidies could be considered as an effective way for promoting extra-familial child care.

The results of this study provide an empirical rationale for the promotion policies such as the incentive programs financed by the Federal government for starting a child-care business. However, it is interesting to note that in spite of the important potential demand for such facilities, not all the available financial resources for the start-ups have been spent. One reason for this surprisingly low demand could lie in the long-term risks that a new facility might fail to reach the economic break-even point. In fact, the actual incentive programs mainly focus on the initial investment costs, which are only a component of overall costs of providing child care services. Generally, the main part of operating costs namely the personnel's annual costs are not covered in these programs. Therefore, in addition to a start-up financing of day care facilities, there is a need for governments' medium and long term commitment that allows these providers to recover their costs. Such commitments, usually expected from the local governments, would be in line with the goal of improving the compatibility of family and career for Swiss women.

Finally, the significant variation of demand across different population groups suggests that promotion policies would be more effective if they could target selected groups of families. This can be considered as a contradiction to an equitable provision of day care services. In 
order to solve this equity problem, governments could consider discount vouchers for families rather than subsidizing the providers. This allows the families to choose their best alternative day care while letting the market mechanism induce a sufficient provision adapted to the demand variations across different regions.

\section{References}

ANDERSON PM., LEVINE P.B., 2000, Child Care and Mothers' Employment Decisions, in Finding jobs: Work and welfare reform, (Card DE, Blank RE, eds.), New York: Russell Sage Foundation, 2000; 420-62.

BATEMAN, I, ... (ET AL), 2002, Economic valuation with stated preference techniques: $a$ manual, Edward Elgar Publishing Limited, Cheltenham, UK.

BEN-AKIVA M., LERMAN S.R., 1985, Discrete Choice Analysis: Theory and Application to Travel Demand, The MIT Press, Cambridge Massachusetts, London, England.

BIROL E., KAROUSAKIS K., KOUNDOURI P., 2005, 'Using a choice experiment to estimate the non-use values of wetlands: the case of Cheimaditida wetland in Greece', Water supply, 5(6): 125-133.

CHAMP P.A., BOYLE K.J., BROWN T.C., 2003, A Primer on Nonmarket Valuation, The Economics of Non-Market Goods and Resources, Ed. Bateman I.J., Kluwe Academic Publishers, Dordrecht, The Netherlands.

CHAPLIN D.D., ROBINS P.K., HOFFERTH S.L., WISSOKER D.A., FRONSTIN P., 1996, The Price Elasticity of Child Care Demand: A Sensitivity Analysis. Unpublished manuscript.

CHEVALIER A., VIITANEN T.K., 2002, The Supply of Childcare in Britain: Do Mothers Queue for Childcare? Unpublished paper, Institute for the Study of Social Change, University College Dublin.

CLEVELAND G., GUNDERSON M., HYATT D., 1996, 'Child Care Costs and the Employment Decision of Women: Canadian Evidence', Canadian Journal of Economics, XXIX(1): 132-151.

CONNELLY R., KIMMEL J., 2003, 'Marital Status and Full-Time/Part-Time Work Status in Child Care Choices', Applied Economics, 35(7), 761-77.

DEL BOCA D., LOCATELLI M., VURI D., 2004, Child Care Choices by Italian Households, Discussion Paper Series, Institute for the Study of Labor, IZA DP No. 983.

GYLDMARK M., MORRISON G.C., 2001, 'Demand for health care in Denmark: results of a national sample survey using contingent valuation’, Social Science \& Medicine, 53, 1023-1036.

GREENE W.H., 2003, Econometric Analysis, 5th edition, Prentice Hall, Upper Saddle River, New Jersey. 
HANLEY N., MOURATO S., WRIGHT R.E., 2001, 'Choice Modelling Approaches: A Superior Alternative for Environmental Valuation', Journal of Economic Surveys, Vol. 15, No. 3, 435-462.

HARRIS K.M., 2002, 'Can High Quality Overcome Consumer Resistance to Restricted Provider Access? Evidence from a Health Plan Choice Experiment', Health Services Research 37:3.

HOFFERTH S.L., WISSOKER D.A., 1992, 'Price, Quality, and Income in Child Care Choice', The Journal of Human Resources, 27, 1: 70-111.

KREYENFELD M., HANK K., 2000, 'Does the availability of child care influence the employment of mothers? Findings from western Germany’, Population Research and Policy Review 19: 317-337.

JAN S., MOONEY G., RYAN M., BRUGGEMANN K., ALEXANDER K., 2000, 'The use of conjoint analysis to elicit community preferences in public health research: a case study of hospital services in South Australia', Aust NZ Journal of Public Health 24(1): 64-70.

LANFRANCHI A., 2002, Schulerfolg von Migrationskindern. Die Bedeutung familienergänzender Betreuung im Vorschulalter, Opladen: Leske + Budrich, Reihe Familie und Gesellschaft, Band 28.

LEIBOWITZ A., KLERMAN J.A., WAITE L.J., 1992, 'Employment of New Mothers and Child Care Choice - Differences by Children's Age’, The Journal of Human Resources, Vol. 27, No. 1, Winter: 112-133.

LOUVIERE J.J., HENSHER D.A., SWAIT J.D., 2000, Stated Choice Methods - Analysis and Application, Cambridge University Press, Cambridge.

LOUVIERE J.J., HENSHER D.A., 1983, 'Using discrete choice models with experimental design data to forecast consumer demand for a unique cultural event', Journal of Consumer research 10(3): 348-61.

MAZZANTI M., 2003, 'Discrete choice models and valuation experiments', Journal of Economic Studies, Vol. 30 No. 6: 584-604.

MICHALOPOULOS C., ROBINS P.K., GARFINKEL I., 1992, 'A Structural Model of Labor Supply and Child Care Demand', The Journal of Human Resources, Vol. 27, No. 1, Winter: 166-203.

MICHALOPOULOS C., ROBINS P.K., 2002, 'Employment and child-care choices of singleparent families in Canada and the United States', Journal of population Economics 15 : 465-493.

MOULTON B.R., 1990, 'Random group effects and the precision of regression estimates', Journal of Econometrics, 32: 385-397.

OECD, 2004, Babies and Bosses: Reconciling Work and Family Life, Volume 3 (New Zealand, Portugal and Switzerland). Paris.

OOSTERBEEK H., GROOT W., HARTOG J., 1992, ‘An Empirical analysis of University Choice and Earnings’, De Economist, 140, Nr. 3 293-309.

Parlamentarische Initiative Anstossfinanzierung für familienergänzende Betreuungsplätze, 2002, Bericht der Kommission für soziale Sicherheit und Gesundheit des Nationalrats vom 22. Februar 2002. 
POWEL L.M., 1997, 'The Impact of Child Care Costs on the Labour Supply of Married Mothers: Evidence from Canada’, The Canadian Journal of Economics, 30, 3: 557-594.

POWEL L.M., 2002, 'Joint Labor Supply and Childcare Choice Decisions of Married Mothers', The Journal of Human Resources, 37, 1: 106-128.

PUNGELLO E.P., KURTZ-COSTES B., 1999, 'Why and How Working Women Choose Child Care: A Review with a Focus on Infancy’, Developmental Review, 19: 31-96.

ROGERS W.H., 1993, Regression standard errors in clustered samples, Stata Technical Bulletin, 13: 19-23 (reprinted in Stata Technical Bulletin Reprints, Vol.3, 88-94).

SCHRÖDER J., 2005, Der Zusammenhang zwischen Erwerbstätigkeit und Fertilität: Ein Überblick über den Forschungsstand, Working Paper, Mannheimer Zentrum für Europäische Sozialforschung, Universität Mannheim.

SOUTAR G. N., TURNER J.P., 2002, 'Students’ Preferences for University: A Conjoint Analysis’, The International Journal of Educational Management 16/1, 40-45.

STEBLER S., 1999, Erwerbsverhalten und Familienpolitik in der Schweiz. Dissertation der Wirtschaftswissenschaftlichen Fakultät der Universität Zürich, Zürich.

STUTZER A., DÜRSTELER R., 2005, Versagen in der staatlichen Krippenförderung Betreuungsgutscheine als Alternative, CREMA, Working Paper No. 2005-26.

STERN S., BANFI S., TASSINARI S., 2006, ed., Nachfrage für Krippen und Tagesfamilien in der Schweiz - Aktuelle und zukünftige Potenziale, Haupt, Bern.

VAN HORN M.L., MULVIHILL B.A., NEWELL W.Y., 2001, 'Reasons for Child Care Choice and Appraisal Among Low-Income Mothers', Child \& Youth Care Forum, 30(4): 231:249.

VERHOEF P.C., FRANSES P.H., 2002, On combining revealed and stated preferences to forecast customer behavior: three case studies, Econometric Institute Report, 2002-04, Erasmus University Rotterdam. 